\title{
E-Procurement In Accounting: A Macro Perspective Of Selection Techniques
}

Saravanan Muthaiyah (E-Mail: saravanan.muthaiyah @ mmu.edu.my), Multimedia University, Malaysia

Murali Raman (E-mail: murali.raman @ mmu.edu.my), Multimedia University, Malaysia

Larry Lombard, Ph.D. (E-mail: lombardl@ mscd.edu), Metropolitan State College of Denver

\begin{abstract}
Selecting an E-procurement accounting package is a complex process because of rapidly changing technology and the variety of options proposed by software providers. There are many eprocurement packages available in the market, but most of these packages simply automate the ordering process. Using an integrated system to place orders over the Internet can save time, reduce postage and paper cost. But without integrating e-procurement packages within a company's finance and accounting systems, one of the largest opportunities for savings is missed out. To achieve full advantage of e-procurement, the procurement system must be integrated not only within the financial system but also with vendors and customers.
\end{abstract}

There are two main categories of e-procurement solutions: 1) buy-side and 2) marketplace. While the full range of benefits might be better secured with buy-side procurement solutions, application costs make marketplace solutions more affordable. For smaller companies, costs of development of buy-side solutions will most often outweigh benefits and therefore marketplace solutions will be more suitable. For large businesses that choose buy-side solutions, careful evaluation is required in selecting the best software that can best suit the company requirements. No matter how good a product is, users must still depend on reliable and continued support from vendors.

\section{Introduction}

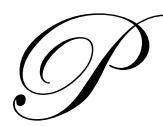

rocurement is the process of purchasing goods and services, whereas e-procurement is the use of Internet technologies to automate the procurement process. It offers a way for businesses to improve the speed and efficiency, and reduce cost of purchasing goods and services. One of the biggest advantages of e-procurement is seen when it is integrated with a firm's accounting package.

According to Forrester Research, strong demand will spur growth of worldwide e-procurement market from US $\$ 3.6$ billion in 1999 to US\$1.375 trillion in 2003. For most companies, the question is not so much if it is time to acquire an e-procurement system but whether to develop a buy side or use a marketplace solution. Eprocurement solutions cost millions of dollars. Detailed attention must be paid when selecting an e-procurement package. It is not uncommon for a company to spend a lot of money and effort on a software solution that does not meet its requirements. The purpose of this paper will help decision-makers in selecting an appropriate eprocurement accounting package that meets business needs.

\section{Problem Statement}

The selection of an e-procurement accounting package can be one of the most frustrating experiences for any company that is considering going online. This is because of rapidly changing technology and the wide-variety of options proposed by the software solution providers. There is no best solution! No single product will suit every

Readers with comments or questions are encouraged to contact the authors via email. 
particular company's needs. The objective is to select a package that best fits a particular company's needs, given the operating environment of a particular firm.

\section{Objective of the research}

The objective of the research is to highlight the importance of e-procurement and assist organizations in selecting appropriate e-procurement software that best fits the needs for an individual firm.

\section{Scope of the research}

This article does not cover smaller companies, as the cost of development of buy-side solutions will most often outweigh the benefits achieved. Marketplace solutions are therefore more suitable for smaller companies. However, this report will help the reader understand the difference between buy-side and marketplace solutions.

This article is aimed primarily towards large companies that want to implement a new e-procurement solution or update an existing one. The article also helps the reader understand what e-procurement is, why there is need for it, and how it can help speed up the procurement process, make the process more efficient and reduce procurement costs.

\section{Survey of Literature}

Andrew Tobin indicates that e-procurement is growing, and vendors are attempting to meet the need in new ways. National Power used to spend $\$ 75$ processing a stationery order worth $\$ 50$, but using software to purchase directly from suppliers over the Internet, the company has reduced purchasing costs to \$10. A recent Goldman Sachs study has shown that companies can save anything from 2 per cent (coal industry) to 39 percent (electronics industry) on their procurement by using automated techniques made available by the Internet. E-procurement packages are now available off-the-shelf, though integration is required. An easy method to get into e-procurement is by joining open communities available on the Internet.

Barry Lacy and Ian Nash recommend that one of the most common ways to implement an "off the shelf" eprocurement system, would be acquisition from either an ERP vendor, or a point-solution provider. The first step in selecting a technology partner and an e-procurement package is to identify the products or services a business is purchasing. Management must consider, whether the main focus of the company is to reduce transactional costs associated with high volume/low value purchase of non-critical supplies or the purchase of direct production raw materials. The business seeking e-procurement should define the external and internal factors such as engagement of eprocurement vendors and capability of internal users to trade electronically with suppliers.

Brandon Coleman believes that an effective accounting software package can help make monitoring finances less cumbersome and help save money at the same time. Selecting effective accounting software can be one of the most difficult tasks a company may face. Coleman recommends taking into consideration the following things when selecting software:

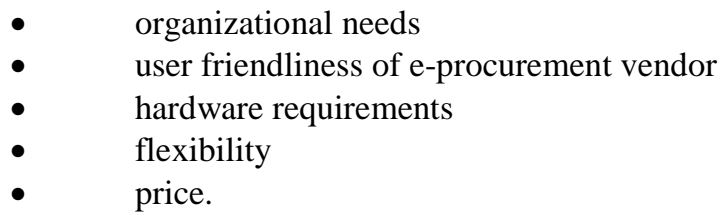

J. Carlton Collins says that the Internet is changing the way businesses conduct business. Company managers must rethink what can be expected from their accounting package. The back-end accounting software should be integrated with the e-procurements solution. Software should be able to publish web catalogs directly from the inventory module in order to deliver real-time information on prices and quantities on hand. Software should also be able to receive orders directly from the web site and import them automatically into the sales order module. Reports should be printed in web page format so that the users can access these reports via the Internet. Other recommended features include: 
- user-friendliness

- $\quad$ foreign currency support

- $\quad$ graphic guidance

- $\quad$ vendor's reliability.

Laurent Ledoux, a manager in the Arthur D. Little's E-Business Center, based in Brussels suggests that most small and medium-size businesses should opt for emerging marketplaces, as the costs of developing procurement systems don't often outweigh the benefits. Large businesses face a difficult choice as their purchasing needs increase, when compared with limited internal capabilities of human resources and skills.

Lou Kabzan, Marcum \& Kliegman, LLP recommend that when companies are in the process of selecting an e-procurement accounting package, careful selection should be made of individuals making the selection decision. The decision committee should list all the requirements and then prioritize them. Once the requirements have been prioritized, then the decision committee should investigate various e-procurement systems that will meet the company's immediate needs and still be flexible enough to offer growth potential. Not only should software be evaluated, but vendor attributes should also be evaluated. The decision committee should consider the following vendor attributes:

- $\quad$ User friendly service

- $\quad$ Keeping the product technologically current

- $\quad$ Providing low-cost software upgrades

Raghunathan, Bhaun (Sept. 1995) carried out a survey and found out that small businesses face a major challenge in selecting an appropriate hardware and accounting software. Large companies typically have resources to appoint a special task force or hire consultants to provide advice on hardware and software acquisitions. The survey showed that most businesses were unfamiliar with various aspects of software acquisition and, rather than spending time and effort in learning, they opted to heed the advice of someone they considered to be knowledgeable. The first three things that most businesses look for when selecting accounting software are:

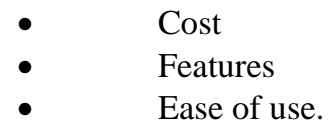

Steven Hornyak and Todd Ostrander (1999) state that e-procurement is fundamentally changing the purchasing process. Employees throughout the organization have the ability to order and receive operational supplies and services from their desktop computer. One of the most misunderstood components of e-procurement is catalog management, the process of consolidating and presenting goods and services offered for online purchase. By applying the business requirements of e-procurement and the "seven C's" of catalog management to solutions selected for business today, companies can save substantially. Coupled with web-based enterprise budgeting and planning, companies can use e-procurement to realize unprecedented cost savings.

Suzanne Braun (Oct 1999) points out that selecting an inappropriate accounting package can be costly to a company. Braun suggests a prioritized list be made of all the tasks needed by the business and software be selected that closely meets the requirements. When considering accounting software, the computer software representative should be asked to demonstrate applications to business functions within the company. Accounting software should be flexible, with the potential of a 3 to 5 year life and the vendor's track record in offering upgrades should be reviewed.

Patrick Coleman recommends that moving a company's procurement to the Internet allows the company to push its purchasing to a few strategic suppliers, thus enabling the business to receive better terms, better discounts and better support. When that happens, the cost savings will boost a company's bottom line. Another factor contributing to the growth of e-procurement is XML. XML provides a common data interchange format, so that companies have the ability to easily communicate electronically with each other. However, most existing XML vocabularies for supply chain transactions can process only simple types of data transfers, not the complex steps inherent in most supply chain transactions. 


\section{Research Methodology}

This paper is based on the information gathered from secondary data such as online journals, reports, magazines and books. E-procurement is a new technology and therefore only limited resources are available that describe the selection criteria of an e-procurement accounting package. Therefore the information was collected to provide an understanding of e-procurement, in terms of: 1) what it is, 2) how it works, 3) how it is integrated with presently developed accounting systems and 4) how to select an e-procurement accounting package for a particular business.

\section{Discussion, Analysis and Findings}

E-procurement solutions can be applied at different levels ranging from information through interaction and integration, to participate in new business models and markets such as web-auctions and virtual marketplaces. Before describing the criteria in selecting an e-procurement accounting package, it is best to understand the following:

- What is e-procurement, and what it has to do with the accounting system?

- What alternatives to e-procurement are available in the market?

\section{What is e-procurement and what it has to do with the accounting system}

Procurement is the process of purchasing goods and services. E-Procurement is the use of Internet technologies to streamline the procurement process. In this sense, most companies are already using e-procurement. However, in its true meanings the entire process of buying and purchasing should be automated and linked with the firm's accounting system.. If the e-procurement is coupled with the financial system, the entire process of procurement begins with collecting product information to payments of bills, which all can be a paperless process. Requisitions are entered only once and can be routed automatically for authorization. This speeds up the process and reduces the chance for errors and omissions.

Once the requisition is approved, the actual purchase can be handled a number of different ways. The employee handling the order can call up electronic catalogs from approved suppliers and order directly from them. There are also online marts and auction sites an employee can access. Some advanced systems can search approved vendors for the lowest price and make the purchase automatically. Once the purchase has been made, the receipt of the goods can be handled electronically, with electronic matching of goods received, purchase order and invoice. In some systems, the supplier is automatically notified that payment has been authorized. This saves the supplier from having to generate an invoice and simplifies the reconciliation process. The best systems are all paperless. The key advantage is that the financial data is automatically updated throughout the process. Thus, real-time computing is achieved. People in accounts payable and purchasing don't have to keep re-entering data, and management always has current and updated information. The biggest saving is in manpower, time, paper and postage. Above all, the process is accomplished faster and eliminates redundant steps.

If the e-procurement solution is not linked with the firm's existing accounting package then e-procurement becomes an isolated step. Instead of moving automatically throughout the process, the purchasing information stops in procurement. The data is stored in a number of different places, which results in considerable extra cost and the potential for errors. In such systems, most of the processes are still being handled manually with paper documents. The supplier still prepares paper invoices and mails them out, management obtains information from several sources, compares current purchases against budgets, with the possibility that the information is not current.

\section{What alternatives to e-procurement are available in the market?}

Electronic Data Interchange (EDI) is a common alternative to e-procurement. EDI is the electronic exchange of routine business transactions. These transactions include:
- $\quad$ Planning
- $\quad$ Pricing
- $\quad$ Purchase orders 


\begin{tabular}{ll} 
- & Inquiries \\
- & Order status \\
- & Test results \\
- & Acknowledgements \\
- & Scheduling \\
- & Shipping \\
- & Receiving \\
- & Invoicing \\
- & Payments \\
\hline
\end{tabular}

EDI is used by the following industries:

$\begin{array}{ll}\text { - } & \text { Retail } \\ \text { - } & \text { Insurance } \\ \text { - } & \text { Education } \\ \text { - } & \text { State and local governmental units } \\ \text { - } & \text { Entertainment } \\ \text { - } & \text { U.S. Governage banking } \\ \end{array}$

EDI allows hundreds of unrelated companies to communicate and process business transaction electronically. The advantages of EDI include:

- A paperless way of conducting business transactions

- $\quad$ One-time data entry

- $\quad$ Error reduction

- $\quad$ On-line data storage

- $\quad$ Faster reporting

- $\quad$ Automated transaction reconciliation

- $\quad$ Time savings

- $\quad$ Efficient transaction handling

- Uniform transaction reporting

Electronic Data Interchange (EDI) operates in the following manner. It has been used mainly to handle large scale purchasing of parts and equipment in the automotive industry. EDI is really only a standard format for transactions, which enables each computer to know where each data field is located. To employ EDI, data needs to be translated into these standard formats. This can either be done by purchasing EDI translation software or by using a third party service. These transactions then have to be transmitted back and forth between trading partners and the business. This is accomplished by connecting computers to a Value Added Network (VAN). The VAN functions as a switching station to route transactions between trading partners. EDI is being Internet-enabled at the moment as well. However, traditional EDI was always too expensive for smaller applications. EDI is no doubt more secure than e-procurement but the costs outweigh the benefits.

\section{Selection of E-procurement solution}

Selecting an e-procurement package is not the same as selecting any other software package. There are many procurement responsibilities in the selection and implementation of E Procurement systems. For example:

- $\quad$ Deciding whether to bring suppliers onto the organization's Intranet

- Deciding whether responsibility for catalogues should be that of the suppliers or the buying organization

- $\quad$ Deciding whether to engage a third party service provider to manage the e-procurement system

- $\quad$ Deciding whether to integrate the system to other systems e.g. the finance system or Enterprise Resource Planning (ERP) System etc.

- $\quad$ Deciding whether to join a Marketplace. 
Basically there are two main categories of an e-procurement solution: buy-side and marketplace.

In buy-side procurement solutions, suppliers send catalogues to buyers. These catalogues are designed and maintained by the buyers so that the data of their selected suppliers are matched to their requirements. On the other hand, e-marketplaces, also called trading communities, have become one of the major attractions in web-based procurement. Virtual brokers called intermediaries organize these marketplaces. They are helping launch communities for vertical markets, enabling participants to buy and sell goods, exchange information, and form partnerships in an industry-specific setting, without having to develop their own buy-side e-procurement system.

Both of these solutions have advantages and disadvantages related to them, for example:

\begin{tabular}{|c|c|}
\hline Buy-Side & Marketplace \\
\hline Advantages: & Advantages: \\
\hline $\begin{array}{l}\text { - A closed environment where the company } \\
\text { owning the procurement system has freedom } \\
\text { to select suppliers of its own choice. }\end{array}$ & $\begin{array}{l}\text { - All the costs such as hardware, development, } \\
\text { maintenance and certain license fees are } \\
\text { shifted to the marketplace and away from the } \\
\text { company. }\end{array}$ \\
\hline $\begin{array}{l}\text { - Benefits are obtained from the advanced } \\
\text { configuration or search facilities that some } \\
\text { suppliers have implemented with a sell-side } \\
\text { procurement solution. }\end{array}$ & $\begin{array}{l}\text { - No need to worry about catalogue manage- } \\
\text { ment and maintenance, as the intermediary } \\
\text { collects all the data and product information } \\
\text { from suppliers, normalizes that data, and then } \\
\text { creates one centralized product catalogue con- } \\
\text { taining all the data to enable buyers to shop. }\end{array}$ \\
\hline - Optimal search facilities. & $\begin{array}{l}\text { - Intermediaries can provide their own value- } \\
\text { added services like buying guides, credit veri- } \\
\text { fication, risk management, shipment, payment, } \\
\text { auctions and exchanges etc. }\end{array}$ \\
\hline Disadvantages: & Disadvantages: \\
\hline $\begin{array}{l}\text { - Software development costs, hardware costs, } \\
\text { license fees, usage fees, training and main- } \\
\text { tenance costs. }\end{array}$ & $\begin{array}{l}\text { - Less than optimal search facilities for each } \\
\text { buyer that buy-side solutions can provide. }\end{array}$ \\
\hline $\begin{array}{l}\text { - Catalogues are designed and maintained by } \\
\text { the buyers; therefore they are forced into a } \\
\text { content maintenance role that can become } \\
\text { burdensome. } \\
\text { - Requires more attention and human resource } \\
\text { skills to keep it in-house. }\end{array}$ & $\begin{array}{l}\text { - Purchasing through a marketplace rather than } \\
\text { directly through the supplier's web site may } \\
\text { prevent buyers from benefiting from the ad- } \\
\text { vanced configuration or search facilities that } \\
\text { some suppliers have implemented with a sell- } \\
\text { side procurement solution. }\end{array}$ \\
\hline
\end{tabular}

\section{Multiple suppliers to multiple buyers in the Virtual Marketplace Model}

The respective advantages of the two solutions depend on the individual industry and products, the power balance between buyers and sellers in the industry, and the importance of the company in a particular industry. Both solutions enable the extension of the supply chain, but this might be a bit more straightforward for buy-side procurement solutions from ERP vendors. 
In conclusion, while the full range of benefits might be better secured with buy-side procurement solutions, applications costs might make marketplace solutions the preferred option.

For smaller companies, the costs of development of buy-side solutions will most often outweigh the benefits and therefore marketplace solutions will best suit such companies. When large businesses decide to choose buyside solutions, companies should carefully evaluate and select the best software provider who can meet their specific requirements. Given below are proposed selection criteria to assist organizations in selecting an appropriate e-procurement package to meet a company's needs.

\section{Proposed Selection Criteria:}

Before selecting an e-procurement package, the decision committee should identify as many e-procurement packages as possible using various information sources. The initial list should include only proven products that potentially meet the organization's needs. After identifying possible software programs, the selection committee should request each software package's sales literature, and search magazine articles for software reviews. Rely on the information gathered to eliminate the software packages that seem less likely to meet the organization's needs. Once the software packages are short-listed, assess them according to the criteria given below:

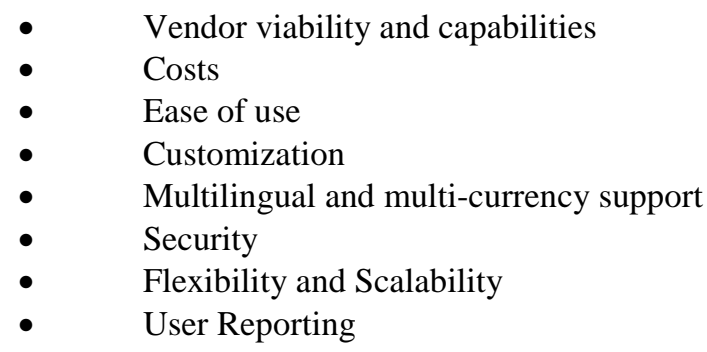

\section{Vendor viability and capabilities}

Many first time e-procurement solutions buyers disregard vendor reliability and focus primarily on the product's quality, price or both. No matter how good a product is, a user still must rely on continued support from the vendor. It is strongly advised to select a vendor who is financially strong, reliable, has the resources to meet a company's requirements and will be available when needed. A proposed criteria for selecting a vendor is given below:

\footnotetext{
- $\quad$ Consider financial strength of vendor

- $\quad$ Obtain customer references

- Inquire about service offerings

- $\quad$ Evaluate sales and marketing capabilities

- $\quad$ Evaluate strength of technology

- Is continued support available after warranty expires
}

If possible contact references supplied by vendors and ask a few simple questions, such as:

- How long has the customer used the product?

- Who performed installation?

- Was the installation satisfactory and done on time?

- $\quad$ Is the customer satisfied with the product?

- What problems has the customer had with the product?

- What limitations has the customer had with the product?

- Would the customer buy the product again?

- $\quad$ Is the customer planning on keeping the product and purchasing technical upgrades as they are made available? 
Usually three good references are enough to make a decision a decision for a particular product and vendor. If the decision is to be made by a committee, then committee members may score each product and the product with the best score would be the one to choose. Vendors with limited resources or technological support should be avoided. The best software vendors are profitable and supported by staffs that are both knowledgeable and large enough to meet the needs of its customers.

\section{Costs}

E-procurement accounting software packages are very costly. Currently, companies are paying millions of dollars for buy-side procurement solutions from Ariba, Commerce One, etc. One of Ariba's customers is Alliant Energy headquartered in Madison, Wisconsin. Alliant Energy was formed through a merger of IES Industries, Interstate Power, and WPL Holdings and is now a major energy services company with growing national and international diversified operations. Alliant Energy uses software from Ariba, called Ariba Buyer to streamline purchasing processes and reduce costs of goods services it purchases by channeling buying to preferred suppliers and taking advantage of economies of scale.

Commerce One provides software, services to companies globally, providing buying organizations visibility and control over inter-enterprise sourcing and procurement processes. By putting these processes on the Internet, Commerce One enables new levels of collaboration and communication between buyers and suppliers. Commerce One solutions reduce cycle times, lower transaction costs, and achieve better pricing for all types of goods and services. Since 1996, Commerce One has helped the world's leading companies, including: Boeing, Deutsche Telekom, General Motors, DaimlerChrysler, and others. Commerce One solutions have generated millions in savings for more than 550 customers worldwide supporting complex purchasing requirements for such industries as automotive, utilities, healthcare, metals and mining, aerospace, and energy. Commerce One technology enables organizations to trade with anyone, anywhere, and at anytime. Companies can engage in mutual transactions - no matter what technology is used, what language is spoken, or what currency is used. Nearly half of most companies' revenues are spent on purchasing activities and one of the fastest and most economical ways to deliver bottom-line results is to reduce the costs of procurement and sourcing. The mission of Commerce One solutions is to give organizations the tools to reduce costs quickly by providing visibility and control over the entire enterprise sourcing and procurement process.

When purchasing a new e-procurement accounting software package, keep in mind it is not only the software price that needs to be considered, but there are other costs too that are directly associated with the package, including:

- Content management and catalogue development, which is the most important and difficult tasks involved with e-procurement. To maintain an in-house environment, it is necessary to spend substantial dollars on training and honing human resources skills. If the company does not have these skills and resources in-house, it may consider out-sourcing these tasks or provide training to its employees. Both of these solutions will also incur extra costs. If the selected e-procurement package does not include the backend ERP system then the integration costs also needs to be considered. The e-procurement package is not much of use if it is not integrated with the backend ERP system. When making a decision, it is necessary to determine the degree of technical support provided with the software and the cost of additional support. Many software companies offer free support for a period of time after the purchase, but will charge support fees after the introductory period of time or for additional modules.

- Hardware cost is another cost that needs to be considered. The existing hardware may not be compatible with the new software package. In addition the existing hardware may not have the required speed or memory to support the new software acquisition. This may require the purchase new hardware, as well. Reasons for purchasing new hardware include:

- Existing hardware may be technologically outdated for the new software and it may not work properly or produce the results as expected.

- Change in operating systems and technologies may require an upgrade in hardware Yesterday's equipment will typically run today's latest operating systems and applications. In fact, keeping old equipment is often more costly than just replacing it. Recall the "sunk cost" theory, that past 
costs invested into equipment are irrelevant, the decision must be based on future cost savings.

$\circ$

Speed demands on hardware keeps increasing. The timesaving alone typically pays back the hardware cost in a matter of months. Newer and faster hardware that crashes less frequently and causes fewer problems always results in time and money savings.

- Implementation of new hardware, consultation, and training costs must also be considered.

\section{Ease of Use}

Another important feature to look for when evaluating e-procurement accounting software is user friendliness. It must be easy for the end-user to search for products, without knowing the product name or product code of the supplier. The user must feel as if he or she is shopping not entering a requisition. It should also be easy for the administrator to implement business rules, and catalog maintenance through visual graphical point-and-click interface linked directly to the back office systems.

Advanced e-procurement systems are using new technologies such as XML to transmit data in standardized format to end-users. Turnkey tools can even capture data from supplier web sites, and pull information into a product index with no human intervention. With these powerful tools, managing catalogs can be a simple process.

A picture is indeed worth a thousand words, but it is probably worth several thousand numbers. Make sure the package in consideration can convert numbers into graphics. Several accounting packages can produce pie, line and area charts from the numerical data.

User friendliness in general is subjective and hard to quantify. What is user friendliness to some is of no significance to others. The basic areas to test include:

- $\quad$ Ease of installation and setup

- Clearly defined screen labels and instructions

- $\quad$ Logical processing and routines that are intuitive

- $\quad$ Easy to understand menus

- $\quad$ Ease of conducting day-to-day operations

Sometimes, vendors allow using their facilities for reviewing and testing their software solutions. If this is not possible ask for live demonstration from the sales representative. Demonstrations help to provide a better understanding of the product and highlight the features that may not have been considered previously.

\section{Customization}

Finding a product that meets all the requirements may be difficult to find. If this is the case, software customization may be necessary. It is advised to check whether the product can be customized, and if it can, whether the customization will meet organization's requirements and the degree of difficulty in accomplishing the customization process. Even though the customization can be very useful as it makes the software specific to organization's needs, there are some problems with it as well. For example, technology changes rapidly and new upgrades may be available every few months. In order to stay competitive, vendors keep on adding new features to their software and allow customers to benefit from the new changes at very minimal charges. But once the product is customized, it can no longer be upgraded without losing those modifications.

There are many levels of customization. The most common place where customization is needed is the financial reports. There may be a need for the new financial reports or edit existing formats. Some products are not flexible enough to produce custom-tailored financial statements.

\section{Multilingual and multi-currency support}

Companies considering e-procurement solutions should bear in mind that they will probably have worldwide customers and suppliers. Therefore, their e-procurement system should be able to print a multilingual product catalog and handle multiple currencies. Only a handful of e-procurement accounting packages process multiple currencies, while others partially support multiple currencies and others do not support this requirement at all. Many 
vendors are using XML to support multilingual catalogs. Some smaller international companies attempt to avoid the complexities of foreign currency translation by offering goods for sale only in their base currencies and by accepting only credit card payments from international customers.

\section{Security}

One of the biggest obstacles in the growth of e-procurement is security. Many companies prefer EDI than e-procurement only because EDI is more secure. But EDI security comes at a price that outweighs its benefits. Close attention should be paid when checking the security of e-procurement solutions. A survey shows that $64 \%$ of the companies rely on password controls when dealing with their suppliers over the Internet, yet passwords alone are unlikely to be that secure. Only $27 \%$ have yet adopted digital certificates to secure e-procurement transactions. The reason for this low adoption rate, is because of the high cost of digital certificate implementation. As more and more digital certificate providers are entering the market, the cost of digital certificates is dropping down. It is advised to select an e-procurement solution that provides digital certification.

\section{Flexibility and Scalability}

The package under consideration should have the ability to integrate with third-party software solutions. It should be flexible enough to implement the buyer's procurement process and support changes in those processes. The needs of an organization keep on changing over a period of time and so the software package should be flexible enough and expandable to support future growth of the company.

\section{User Reporting}

Another important feature that cannot be missed is the ability to generate web-based reports. These reports allow users to perform advanced analysis quickly over the Internet. Browser based reporting capability provides users with access to all their transactions.

\section{Additional features to look for}

The e-procurement package should also be able to:

- $\quad$ Publish web catalogs directly from the inventory module.

- $\quad$ Retrieve orders directly from the web site and import them automatically into the sales order module.

- $\quad$ Allow users to access reports and accounting data across the Internet.

- $\quad$ Let remote users securely enter accounting data and transactions via the web.

- $\quad$ Send e-mail reports and messages when triggered by predefined events.

\section{Conclusion}

Selecting an e-procurement package is not the same as selecting any other software package. There are many procurement responsibilities in the selection and implementation of e-procurement systems. Most small and medium-size businesses will probably be better off selecting marketplace solutions, as the cost of developing eprocurement systems does not outweigh the benefits. Large businesses face a difficult choice. Their buying power and internal capabilities might direct them toward buy-side solutions.

Buy-side e-procurement solutions cost millions of dollars. Therefore, careful and detailed attention must be paid when selecting one. All organization's needs must be identified, requiring consultation with end users. Software should meet the organization's needs as close as possible. After considering the e-procurement packages available, a short-list should be made and then selection of the package that best meets business requirements. No matter how good a product is, users still must rely on continued support from the vendor. Vendor's access, reputation and reliability should always be an overriding consideration. 


\section{References}

1. Annamarie Freas (2000), Research Report on E-Procurement (Catalog number 00-003)

2. Barry Lacy and Ian Nash, A one-stop shop? Turning hype into reality

3. Ben Schaab (1997), Choosing the Right Accounting Software

4. Brandon Coleman, Finding the right Accounting Software Package

5. Frank E. Benassi, E-Procurement: One-stop shopping and lower prices

6. J. Carlton Collins, How to select the Right Accounting Software - Part 3 Handling the Web and International Commerce

7. Laurent Ledoux, E-Procurement: Going for Buy-side or Marketplace Solutions?

8. Melinda Johnson (2000), E Procurement at the Turn of the Millennium: A New Frontier

9. Michael J. Budiac, Top Ten Criteria for Selecting Accounting software

10. Patrick Coleman (2000), e-Procurement: A Pragmatic Look at Supply Chain Automation Via the Internet, http://www.ebizquardrant.com/scm/coleman_l.html

11. Suzanne Braun (Oct 1999), How to Select Accounting Software

12. CNET Enterprise, Industry Snapshot: Accounting

13. CPA Online, inSITE Magazine (Issue 1.00), "Selecting Accounting Software: A User's Point of View"

14. Ctsguides.com, "Accounting and Business Software Selection Secrets", http://www.ctsguides.com

15. Emergis, e-Procurement Newsletter, http://www.emergis.com

16. Intel Corporation, Dynamic E-Procurement - "What is E-Procurement"

17. Practitioner's Publishing Company, Nonprofit Financial and Accounting Manual - Selecting Software

18. Royal Bank Financial Group, Royal Bank of Canada (1995), What is e-Procurement?

19. UK accountancy program selection - How to select an accounting program

20. Ybn.com (Aug 2000), Fill in Your Technology GAAP, http://www.ybn.com

21. http://www.ledisource.com/edi101.html

22. http://www.ariba.com/

23. http://www.commerceone.com/company/ 
Notes 